\title{
Produção acadêmica sobre gestão de recursos humanos em ongs: uma análise no campo da administração
}

O presente artigo aborda a produção bibliográfica sobre gestão de recursos humanos em Organizações Não-Governamentais (ONGs), focalizando periódicos e produções científicas na área da Administração. Tem como objetivo ampliar o conhecimento sobre o tema, auxiliando futuras investigações, bem como permitir uma reflexão mais crítica sobre as interlocuções dessa área de conhecimento sobre o assunto. Os resultados obtidos permitem identificar uma prevalência das subáreas de Finanças e Economia como ponto de origem de boa parte dos artigos publicados nos periódicos investigados, seguida pelas subáreas de Organizações, Sistemas e Métodos e de Recursos Humanos. A análise dos resultados recomenda o avanço da pesquisa científica em torno das ONGs, de forma a qualificar melhor o debate em torno dessas instituições.

Palavras-chave: Organizações Não-Governamentais; Terceiro Setor; Gestão de Recursos Humanos.

\section{Academic production on human resources management in NGOs: an analysis in the field of administration}

\begin{abstract}
This article discusses the bibliographic production on human resources management in non-governmental organizations (NGOs), focusing on journals and scientific works in the administration area. It aims to expand the knowledge on the subject, helping further investigations, as well as allowing a more critical reflection on the dialogues of this area of knowledge on the subject. The results allow us to identify the prevalence of sub-areas of Finance and Economics as a good point of origin of the articles published in the journals studied, followed by subareas Organisations, Systems and Methods and Human Resources. The analysis recommends the advancement of scientific research around the NGOs in order to better qualify the debate on these institutions.
\end{abstract}

Keywords: Non-governmental Organizations; Third Sector; Human Resource Management.

Topic: Teoria Geral da Admistração

Reviewed anonymously in the process of blind peer.

Joao Cesar de Freitas Fonseca

Universidade Federal de Minas Gerais, Brasil

http://lattes.cnpq.br/0016680859233685

joaocesar.fonseca@yahoo.com.br

\section{Thiago Lizardo Silva}

Pontifícia Universidade Católica de Minas Gerais, Brasil

http://lattes.cnpq.br/9931276115086961

thiagolizard@live.com
Received: 09/02/2016

Approved: 11/07/2016
Referencing this:

FONSECA, J. C.; SILVA, T. L.; VIANA, A. F.. Produção acadêmica sobre gestão de recursos humanos em ongs: uma análise no campo da administração. Revista Brasileira de Administração Científica, v.7, n.2, p.275-287, 2016. DOI: http://doi.org/10.6008/SPC2179$\underline{684 X .2016 .002 .0018}$ 


\section{INTRODUÇÃO}

Uma das características da contemporaneidade é a maior diversidade quanto às formas de gestão e modelos estruturais adotadas pelas organizações (ZARIFIAN, 1997; RUAS et al., 2008; FISCHER et al., 2010). Perceptível tanto no setor público quanto no privado, esse aumento da complexidade organizacional atinge também as instituições criadas por iniciativa da sociedade civil de uma forma geral, fazendo com que o processo de compreensão do surgimento e transformação das Organizações Não-Governamentais (ONGs) fique progressivamente mais dinâmico e convidando pesquisadores e centros de estudo ao exame desse fato social (CARDOSO et al., 2014; ASSIS et al., 2012; FONSECA et al., 2012).

Atualmente, existem no Brasil e no mundo várias organizações que se identificam como ONGs, havendo um intenso debate quanto à sua natureza e quanto às possibilidades de englobá-las em um único conceito. Em outras palavras, pode-se dizer que essa sigla - de uso consagrado no senso comum - carrega múltiplos significados, principalmente quando se tem em vista que a definição do seu escopo começa sendo feita, a priori, por exclusão: "não-governamental".

Importa observar, preliminarmente, que as ONGs integram o arcabouço do chamado Terceiro Setor, referindo-se às organizações da sociedade civil que se distinguem daquelas vinculadas ao Estado (primeiro setor) e ao Mercado (segundo setor). O termo "ONG" constitui a versão para a língua portuguesa de uma noção cunhada originariamente na língua inglesa: Non-Governmental Organization (NGO). Embora alguns autores informem sobre o uso desse termo desde o final do século XIX, nota-se que o mesmo ganhou maior popularidade ao ser utilizado, no início do século XX, para designar diferentes entidades executoras de projetos humanitários, de interesse público e/ou coletivo (WILLETS, 2006; LEWIS, 2001).

Ao defender seu argumento sobre a importância de se pensar na produção de conhecimento administrativo para o Terceiro Setor, autores como Machado et al. (2007) defendem a importância de se delimitar, com maior precisão, o escopo conceitual, o objeto de estudo e a singularidade ante os outros tipos de organização com tradição em pesquisa. Na mesma direção caminham os apontamentos de Sampaio (2004):

Não há de ser pela existência de diferenças entre as organizações [não-governamentais] que se inviabilizará sejam estudadas sob uma só designação, desde que haja um sistema classificatório que permita distinguir suas peculiaridades e que haja fenômenos comuns e gerais, próprios deste grupo de organizações como um todo. Entende-se que a criação de organizações em torno do princípio da "não-lucratividade", comum a todas elas, impõe de alguma forma a existência desses fenômenos sociais e grupais comuns, no contexto de uma teoria da ação social.

No Brasil, como na América Latina de forma geral, o histórico das ONGs inicialmente espelha e reinventa o histórico de suas congêneres do Primeiro Mundo, referindo-se às organizações formadas por grupos religiosos, mas também abarcando os grupos interessados no enfrentamento dos governos autoritários vigentes especialmente a partir dos anos 60; os segmentos preocupados com as demandas de desenvolvimento das sociedades (década de 70) ou os grupos voltados para as questões ambientais (anos 80), para citar apenas algumas. Pode-se considerar que a história das ONGs no Brasil constitui um processo de apropriação de um conceito, do ponto de vista sócio histórico, uma vez que aqui essas organizações vão ganhar características específicas (FERNANDES, 1997; LANDIM, 1993; 1998). 
Uma das mais fortes expressões das ONGs no Brasil é a Associação Brasileira de Organizações NãoGovernamentais (ABONG), fundada em 1991 e que vem ajudando a formatar um conceito local desse tipo de organização. Segundo a ABONG (2013):

São consideradas Organizações Não Governamentais-ONGs, as entidades que, juridicamente constituídas sob a forma de fundação ou associação, todas sem fins lucrativos, notadamente autônomas e pluralistas, tenham compromisso com a construção de uma sociedade democrática, participativa e com o fortalecimento dos movimentos sociais de caráter democrático, condições estas, atestadas pelas suas trajetórias institucionais e pelos termos dos seus estatutos.

Numa das publicações da ABONG, Landim (1996, p. 9) lembra que o termo ONG se refere a "uma categoria que vem sendo socialmente construída em tempos recentes, usada para designar um conjunto de entidades com características peculiares e reconhecidas pelos seus próprios agentes, pelo senso comum ou pela opinião pública".

Outros autores, como Cabral (1998) e Paiva (2003), oferecem ênfase sobre as caracterizações das ONGs no espectro político e ideológico, fazendo notar a complexidade desse tipo de organização:

Na América Latina, a partir da segunda metade da década de 60, a reapropriação da identidade ONG deu um sentido particular à ideia de não-governamental. Tal expressão passa a significar aqui rejeição às formas tradicionais de poder, dando origem a um discurso próprio de existência a partir da negação da atuação do Estado - que naquela época significava ditadura militar, da produção científica distanciada da sociedade e das formas assistencialistas de apoio social, cada qual com seus conflitos particulares. (CABRAL, 1998)

Após a realização da Eco- $92^{1}$ nota-se que as ONGs passam a incluir, com expressiva ênfase, as questões ambientais na sua pauta de negociações, tanto junto aos governos quanto ao empresariado. Essa expansão do universo temático abordado pelas ONGs vai contribuir no aumento da diversidade de arranjos institucionais apresentados para corresponder aos múltiplos anseios envolvidos. É na forja constituída pelo diálogo entre esses atores que irá se constituir o marco regulatório das ONGs, atualmente expresso em grande parte pela Lei no 13.019 (BRASIL, 2014).

Assim, torna-se evidente que essas instituições, mesmo que em certa medida representem uma proposta de suprir carências ou desenvolver uma comunidade local, sinalizam também uma forma de negação da atuação tradicionalmente efetivada pelo Estado. Trata-se, essencialmente, do debate feito por autores como Fernandes (1997), sobre a relação entre o público e o privado e da articulação de interesses dos diferentes atores sociais envolvidos. Devido a isso, é razoável considerar que o surgimento e crescimento das ONGs, em quaisquer sociedades, vinculam-se a três grandes motivações, as quais podem ser utilizadas como um parâmetro classificatório dessas entidades (GOHN, 2000; SAMPAIO, 2004; FONSECA et al., 2012).

A primeira delas diz respeito à noção de assistência, destinadas a suprir as carências de uma determinada parcela da população. Tanto no Brasil quanto em outros países, essas ONGs atuam junto a grupos de elevada vulnerabilidade socioeconômica e é frequente adotarem uma orientação religiosa específica, com maior ou menor grau de visibilidade.

A segunda motivação diz respeito aos anseios de participação social, característicos inclusive de agrupamentos onde as necessidades básicas dos cidadãos já se encontram relativamente asseguradas.

${ }^{1}$ A Eco-92 foi uma conferência das Nações Unidas que ocorreu no Rio de Janeiro em 1992 e tinha como principal objetivo discutir questões sobre desenvolvimento e meio ambiente. É considerada um marco na estruturação das ONGs no Brasil. Mais informações em Novaes (1992). 
Embora tenham atuação nos países ditos periféricos, usualmente essas ONGs têm suas bases instaladas nos países de primeiro mundo. Estão frequentemente vinculadas a grupos de forte orientação fundamentação político-partidária, mas também associam-se a igrejas, grupos acadêmicos, movimentos artísticos e outros.

A terceira motivação volta-se para a perspectiva desenvolvimentista, aliada à noção de que as ONGs teriam a flexibilidade necessária para permitir ações mais rápidas e eficazes, superando as limitações que as instituições públicas apresentariam. Um exemplo desse grupo é oferecido por Wanderley (1998), segundo o qual, na perspectiva desenvolvimentista adotada pelo Governo Brasileiro a partir dos anos 70, desenvolverse significava atingir o modelo das sociedades avançadas ou modernas e crescimento econômico estava fundamentalmente relacionado à aceleração da industrialização que, por sua vez, eliminaria o atraso e a pobreza. Apontava-se para a possibilidade de mudanças estruturais e por isso uma das metas era mobilizar vários grupos da sociedade para se organizarem em defesa das reformas de base, agrária, urbana, tributária, entre outras.

O histórico das ONGs no Brasil contemporâneo é marcado pela promulgação da Lei 13.019, em 2014 (BRASIL, 2014). Visando a criação de normas jurídicas gerais para parcerias voluntárias entre Estado e sociedade civil, essa norma pretende reduzir parte da burocracia presente até então enfrentadas pelas ONGs, além de regulamentar as OSCs (Organizações da Sociedade Civil). Outro aspecto relevante é que a lei em questão está relacionada com a intensificação da fiscalização. Afirma-se isso, pois além de ocorrer a adesão dos princípios contábeis pelas Organizações da Sociedade Civil (OSCS), o que evita qualquer tipo de autuação fiscal por não pagamento de tributos, também serão exigidos documentos como: prova da propriedade ou posse de imóvel e Certidões de Regularidade (fiscal, previdenciária, tributária, de contribuições, de dívida ativa). De forma geral, autores como Durão (2014) enfatizam que esse marco legal ainda não logrou reduzir significativamente as contradições e tensionamentos da sociedade em relação às ONGs.

\section{REVISÃO TEÓRICA}

\section{Distribuição, Expansão e Financiamento das ONGs no Território Brasileiro}

A partir da década de 90, fica mais evidente a aceleração do ritmo de crescimento das ONGs no Brasil. Landim et al. (2002) lembram que a interação capitaneada por atores vinculados a grupos específicos como a ABONG (representando as ONGs, de forma geral), a Comunidade Solidária (representando o governo) e o Grupo de Institutos, Fundações e Empresas - GIFE - (representando o empresariado), incluía também organizações da sociedade civil de origem variada, como clubes de serviço (como Lions e Rotary); entidades assistenciais de origem religiosa plural (como o Lar Fabiano de Cristo, da área espírita, ou a Pastoral da Criança, católica, ou ainda a Vinde, evangélica); ONGs (como a FASE, IBASE, ISER, POLIS); fundações, (como a Vitae) e várias outras organizações (como a Rede de Formadores de ONGs, a Federação das APAEs, a Associação de Gerontologia, o Fórum Nacional da Ação da Cidadania, o Fórum Brasileiro de ONGs e movimentos sociais para o meio ambiente e outros). Da movimentação dessas entidades, resultar a modificação do enquadramento legal das ONGs que prevaleceu até recentemente (BRASIL, 1999). 
Segundo Gohn (1997), o aumento número de ONGs pode ser relacionado com a progressiva perda de força mobilizadora dos movimentos sociais, que passaram a adotar uma proposta de integração, diferente da ação contestadora dos anos 70. Uma marca desse período é o aumento das parcerias com o poder público que, em muitos casos, aprimorava estratégias de controle dos processos de gestão das ONGs, na expectativa de melhor aferição dos resultados. Tal crescimento pode ser verificado a partir de alguns mapeamentos feitos por diferentes fatores sociais, voltados para a descrição/identificação das ONGs no território brasileiro (IBGE, 2010; MAGALHÃES, 2010)

O crescimento das ONGs pós Eco-92 já começava a ocorrer em grande escala, afinal isso envolvia a organização se mobilizando em prol da sociedade e ocorria com várias finalidades sociais como: filantropia, ambientalismo, desenvolvimentistas e as cidadãs. Gohn (2000) identificou quatro tipos de organizações nãogovernamentais atuando no Brasil: as caritativas, as desenvolvimentistas, as ambientalistas e as cidadãs. “Apenas uma parcela das ONGs cidadãs evocam o mundo da política, da participação, ao contrário das [...] assistencialistas" (GOHN, 2000).

Em 2010, um estudo publicado pelo IBGE informava sobre a quantidade de instituições existentes no país que não pertenciam ao setor estatal e nem ao mercado, ou seja, as instituições do terceiro setor. Nesse estudo, foi possível identificar 290.692 instituições registradas oficialmente e classificadas como Fundações Privadas e Associações sem Fins Lucrativos (FASFIL²) distribuídas por todo o território brasileiro (IBGE, 2010).

Essas instituições foram classificadas de acordo com áreas específicas em que atuavam e seguiam a seguinte distribuição: $28,5 \%$ contribuíam na área da religião; $15,5 \%$ em partidos políticos, sindicatos, associações patronais e profissionais; $14,6 \%$ em desenvolvimento e defesa de direitos; $12,7 \%$ em cultura e recreação; $10,5 \%$ em assistência social; $6,1 \%$ em educação e pesquisa; $2,1 \%$ em saúde; $0,8 \%$ em meio ambiente e proteção animal; 0,1\% em habitação, e, por fim, 9,3\% foram classificadas como "outras instituições privadas sem fins lucrativos", já que exerciam atividades não especificadas anteriormente.

Cabe informar que, para a realização da pesquisa, o IBGE utilizou para a conceituação de FASFIL as organizações cadastradas no CEMPRE (Cadastro Central de Empresas), da base de dados do IBGE, que atendiam simultaneamente as seguintes características: (a) Ser uma organização privada; (b) Sem fins lucrativos, ou seja, que não efetue distribuição de lucros e dividendos entre seus sócios; (c) Institucionalizada, que esteja constituída legalmente; (d) Autoadministrada, capaz de gerenciar suas próprias operações; (e) Voluntária, isto é, podem ser formadas por qualquer grupo de pessoas e as atividades da entidade é livremente decidida por sócios e/ou fundadores.

De acordo com a pesquisa feita por Magalhães (2010), através de uma iniciativa do Centro de Estudos do Terceiro Setor (CETS) da Fundação Getúlio Vargas (FGV), foi possível criar o documento chamado "Mapa do Terceiro Setor" que tinha como principal objetivo a construção de uma base sólida de informações consideradas relevantes para ajudar organizações do terceiro setor a manter o seu trabalho e a gerir os seus recursos de maneira mais assertiva.

\footnotetext{
${ }^{2}$ O termo FASFIL foi utilizado somente nesse estudo de levantamento do IBGE. Vale lembrar que as ONGs estão incluídas dentro da abordagem do termo FASFIL (IBGE, 2010).
} 
No Mapa do Terceiro Setor é possível conferir a distribuição das Organizações Não- Governamentais no Brasil. A região Sudeste tem a maior concentração dessas instituições, com $48 \%$ do total registrado; em seguida vem a região Norte, com 35\%; por fim, com menor concentração de ONGs, temos as regiões Sul, Nordeste e Centro-oeste, com $11 \%, 4 \%$ e $2 \%$, respectivamente (MAGALHÃES, 2010).

Quanto aos recursos utilizados para a execução de suas atividades, nota-se uma diversidade relativamente expressiva em suas fontes de financiamento. Segundo Magalhães (2010), as principais formas de captação de recursos financeiros são: as parcerias com órgãos governamentais na execução de políticas públicas; a cooperação internacional (seja de caráter público ou privado); contribuições associativas, que se baseiam no recebimento de contribuições financeiras de seus associados ou contribuintes; doações de empresas e/ou indivíduos e também por vendas de produtos (camisetas, acessórios, livros, etc.) ou prestação de serviços, desde que os recursos recebidos sejam investidos dentro da organização e estas atividades não sejam consideradas como lucrativas.

No caso de parceria com órgãos governamentais, as instituições que atuam em áreas típicas do poder público e que apresentem relevância social em suas atividades, geralmente seguem algumas normas das Organizações da Sociedade Civil de Interesse Público (OSCIP) para que se torne possível a captação de recursos financeiros do estado, executando o procedimento de qualificação junto ao Ministério da Justiça. Essa qualificação é opcional e implica no cumprimento de determinados procedimentos, como a publicação anual da prestação de contas, elaboração de documentos contábeis (balanço patrimonial, demonstrações de origens de recursos, auditorias, etc.) por um contador registrado e que deverá seguir as Normas Brasileiras de Contabilidade (CARDOSO et al.,2014).

Em relação ao financiamento feito pelo setor privado, Cunha et al. (2012) esclarecem que os critérios para a tomada de decisão sobre o direcionamento de recursos para ONGs usualmente incluem os seguintes aspectos: informações sobre a eficiência em alocar recursos; a estabilidade financeira; a reputação da organização e as informações disponibilizadas sobre a missão da entidade e situação dos beneficiários.

É razoável considerar que a origem, o volume e a regularidade dos recursos disponíveis poderão afetar significativamente os modelos de gestão, especialmente no que diz respeito às práticas e políticas de recursos humanos. Tais implicações tem sido alvo do interesse de vários pesquisadores ligados ao campo das ciências administrativas. Drucker (1989) defende a necessidade de profissionalização dos indivíduos que atuam nesse segmento, reforçando a perspectiva de uma transposição de modelos de gestão do Primeiro e do Segundo Setor:

As organizações não lucrativas estão, é evidente, ainda dedicadas a 'fazer o bem'. Mas também já verificaram que as boas intenções não podem substituir a gestão e a liderança, a responsabilidade, o desempenho e os resultados. Estes requerem a gestão e isso, por sua vez, começa com a missão das organizações.

Falconer (1999), por exemplo, afirma que o aperfeiçoamento da gestão das ONGs teria um papel importante para criar "uma relação ideal onde o bom gerenciamento permitiria alcançar resultados positivos que, por sua vez, permitiriam a captação de recursos suficientes e a atração de profissionais qualificados, superando as adversidades do meio". 
Mello et al. (2008), Teodósio (2002) e Bose (2004), entre outros, recuperam boa parte da discussão pertinente ao que parece ser um elemento central da gestão nas ONGs: o conflito entre pelo menos duas linhas centrais de ação, que refletem compreensões e paradigmas diferentes de gestão. De um lado, a racionalidade instrumental - referente às ferramentas gerenciais - e de outro, a racionalidade substantiva relativa aos valores organizacionais. Optar pela primeira linha (mais próxima da profissionalização) poderia significar maior controle e definição de responsabilidades, mas também o distanciamento dos ideais fundantes da organização. Já o alinhamento à segunda orientação (valores), poderia significar maior coesão e identificação grupal, a partir do fortalecimento dos laços sociais e do incentivo à criatividade, ao mesmo tempo em que poderia também reduzir o controle e dificultar a sistematização de procedimentos.

Importa considerar que essa dinâmica conflituosa, estabelecida no interior das ONGs, encontra-se afetada pelas mudanças constantes de regulamentação que o campo do Terceiro Setor vem experimentando de forma geral, em especial na sociedade brasileira (VOESE et al., 2011). Tais mudanças refletem as movimentações políticas, econômicas e sociais e podem ser consideradas como um reflexo das tentativas de reorganização da própria sociedade, frente aos múltiplos interesses que a constituem (LANDIM, 2002)3.

Certamente, é oportuno também lembrar que um dos níveis dessas alterações ocorre no interior das organizações, tanto públicas quanto privadas, provocando seus reflexos e desdobramentos no terceiro setor em geral e nas ONGs, em particular.

\section{Mobilizando Pessoas: a Gestão de Recursos Humanos no Terceiro Setor}

Relatando os trabalhos de pesquisa do Programa de Estudos da Gestão Social (PEGS) da Fundação Getúlio Vargas, Tenório (2005), enfatiza a importância de aprofundar os estudos sobre a Gestão das ONGs e afirma que, para superar os desafios que se apresentam a partir das transformações sociais que experimentam, as ONGs "têm que pensar em acrescentar às suas peculiaridades novos instrumentos de gestão, dotando seus quadros de habilidades, conhecimentos e atitudes que assegurem, ao fim e ao cabo, o cumprimento dos objetivos institucionais". Para esse autor, as ações necessárias para atingir esses objetivos seriam: trabalhar por meio de redes; identificar claramente produtos, áreas de atuação e cidadãosbeneficiários; compartilhar ou dividir mercados; criar mecanismos mais eficazes de controle que possibilitem avaliar o impacto das ações executadas; ganhar mais visibilidade perante a sociedade.

Em um interessante estudo sobre ONGs em Alagoas, Carvalho (2000) alerta para a ambivalência de situações experimentadas pelos gestores dessas entidades. Por um lado, a profissionalização da gestão, com maior ênfase nas capacidades técnicas dos colaboradores, pode significar maior possibilidade de ajustamento de processos de trabalho, maior facilidade de captação de recursos e maior ajustamento aos parâmetros normativos (leis, resoluções, etc.). Por outro lado, a valorização dos ideais e do envolvimento afetivo dos membros da instituição, que pode implicar em maior nível de comprometimento institucional, maior capacidade de aproveitamento dos recursos disponíveis e redução dos níveis de turn over.

\footnotetext{
${ }^{3}$ Uma observação interessante nesse sentido é feira por Zanni (2005), ao analisar a competição entre ONGs por recursos financeiros, reproduzindo um paradigma próprio das organizações com fins lucrativos.
} 
Pode-se dizer, portanto, que o terceiro setor enfrenta grandes dificuldades quanto aos processos de gerenciamento das instituições a ele vinculadas, que vão desde a captação de recursos até a gestão de pessoas, principalmente quando se considera que muitos dos colaboradores são voluntários (SAMPAIO, 2004). Dessa forma, é frequentemente exigida do gestor uma postura diferenciada, na medida em que convoca elementos de uma ordem mais subjetiva do que o usual. É comum, por exemplo, a demanda de que o gestor seja uma pessoa "carismática", demanda que se apresenta com muito maior frequência, se comparada com os requisitos solicitados aos gestores de instituições privadas (CARDOSO et al., 2010).

Com base na pesquisa realizada por Garay (2011), observa-se que a estrutura organizacional das entidades do terceiro setor tende a ser mais simplificada, pois a grande maioria dessas organizações são de pequeno porte ${ }^{4}$. Além disso, geralmente contam com recursos abaixo do ideal, grande parte dos profissionais da área são voluntários e com níveis de qualificação e especialidade variados, sendo que também há uma grande diversidade de perfil pessoal e profissional. Finalmente, ainda segundo esse mesmo autor, nota-se que os líderes nessas entidades normalmente são carismáticos e participativos, e em geral exercem um papel central na sensibilização para captação de recursos e mobilização dos colaboradores.

Como em outras áreas do conhecimento, acredita-se que a produção científica produzida em torno do assunto pode vir a contribuir para o aprimoramento das situações práticas de gestão, fazendo pensar nos chamados usos sociais da ciência (BOURDIEU, 2004). No caso específico das ONGs, a breve descrição realizada sobre o estado da arte envolvendo o tema reafirma essa perspectiva. Partiu-se de hipótese de que existe uma a demanda do campo por estudos desse gênero. Assim, optou-se no presente trabalho por uma pesquisa bibliográfica, em torno das publicações na área da Administração sobre a gestão de Organizações Não-Governamentais, de forma a tentar traçar, ainda que parcialmente, um recorte das possíveis contribuições da academia em torno dessa questão.

\section{METODOLOGIA}

Esta pesquisa foi desenvolvida por meio de um levantamento bibliográfico, realizado em 2014 e 2015, vinculado a outro projeto de pesquisa, proposto pelos alunos de graduação ${ }^{5}$. Foram investigadas as publicações efetivadas por periódicos da área de Administração, no período de 2009 a 2013, utilizando como parâmetro a ocorrência das expressões "gestão no terceiro setor", "recursos humanos no terceiro setor", "gestão de pessoas em ONGs" no campo palavras-chave. O objeto de estudo foi coletado por meio do Banco de Teses da Capes, a Scientific Electronic Library Online - Scielo e alguns redirecionamentos do google acadêmico 6 .

Toda a documentação utilizada foi fixada materialmente e suscetível de ser utilizada para consulta, estudo ou prova. Como já ressaltado, a pretensão da pesquisa consistia em coletar dados sobre a

\footnotetext{
${ }^{4}$ São consideradas empresas de pequeno porte (EPP) aquelas que possuem até 99 funcionários e que o seu faturamento bruto anual fique entre $\mathrm{R} \$ 360.000$ e $\mathrm{R} \$ 3,6$ Milhões, tratando-se apenas de uma analogia entre ONGs e EPPs, tendo em vista que se tratam de diferentes tipos de organizações. ${ }^{5} \mathrm{O}$ projeto originalmente proposto intitulava-se "Gestão de pessoas no terceiro setor: dificuldades enfrentadas pelas organizações filantrópicas na gestão dos recursos humanos e as consequências disso na sociedade".

${ }^{6}$ Não foram utilizados artigos do EnANPAD tendo em vista que, de acordo com o Documento de Área 2013, publicado pela CAPES, foi decidido que, gradualmente, a área deixaria de valorizar os eventos como produção bibliográfica (CAPES, 2013).
} 
administração de Organizações não governamentais (ONGs), instituições sem fins lucrativos e a questão filantrópica, para que este estudo facilite outras pesquisas futuras. Em função do objetivo descrito foram selecionados somente periódicos feitos no Brasil, visando verificar as universidades e locais que mais publicaram e que estão publicando, além da qualidade dos artigos, definida em função do reconhecimento da CAPES

Segundo Gil (2002), o método bibliográfico permite ao investigador a cobertura de uma gama de fenômenos muito mais ampla do que aquela que poderia pesquisar diretamente. Esta vantagem se torna particularmente importante quando o problema de pesquisa requer dados muito dispersos pelo espaço. Além disso, a pesquisa bibliográfica é indispensável para a realização de estudos históricos, servindo também como estratégia facilitadora para iniciar na prática da investigação científica aqueles pesquisadores com pouca experiência, como acontece com alunos de graduação.

Revisões bibliográficas servem de base para que outros pesquisadores venham a utilizá-la como instrumento de suporte para suas pesquisas e investigações futuras. Outro fator relevante desse tipo de pesquisa é o fato de que ela também pode ajudar os pesquisadores a encontrar áreas que tem recebido menos atenção das últimas publicações segundo (WEBSTER et al., 2002).

Quanto a classificação dos periódicos, grande parte dos artigos do campo da Administração, Ciências Contábeis e Ciências Sociais Aplicadas estão com notas entre A2 e B4, utilizamos o sistema WEBQUALIS CAPES para verificar a nota atribuída a cada periódico consultado, na tabela abaixo, é possível conferir os periódicos utilizados como fonte para a captação dos artigos da amostra bem como a nota atribuída no sistema.

Tabela 1: Notas Atribuídas aos Periódicos Consultados.

\begin{tabular}{|l|l|l|l|}
\hline Nome do periódico & Nota & Nome do periódico & Nota \\
\hline Revista de Contabilidade e Organizações - USP & B1 & Revista Contemporânea de Contabilidade - UFSC & B1 \\
\hline $\begin{array}{l}\text { Revista Brasileira de Administração Científica - Escola Superior } \\
\text { de Sust. }\end{array}$ & B3 & Revista de Gestão, Finanças e Contabilidade - UNEB & B3 \\
\hline Revista de Administração Pública FGV & A2 & Revista da Micro e Pequena Empresa - FACCAMP & B3 \\
\hline Revista da Universidade Vale do Rio Verde & B4 & Perspectivas em Gestão \& Conhecimento - UFPB & B3 \\
\hline $\begin{array}{l}\text { Revista de Contabilidade do Mestrado em Ciências Contábeis } \\
\text { da UERJ }\end{array}$ & B3 & $\begin{array}{l}\text { Reunir: Revista de Administração, Contabilidade e } \\
\text { Sustentabilidade -UFCG }\end{array}$ & B4 \\
\hline Revista de Administração USP & A2 & Contabilidade Vista \& Revista UFMG & B1 \\
\hline Gestão.Org UFPE & B3 & Teoria e Prática em Administração - UFPB & B4 \\
\hline ConTexto UFRGS & B3 & Gestão \& Regionalidade - USCS & B1 \\
\hline Psicologia e Sociedade UFRGS & A2 & & \\
\hline
\end{tabular}

Foram utilizados artigos produzidos pelas principais universidades brasileiras que publicam pesquisas na área, como a Universidade de São Paulo, com amostra de 5 artigos, a Pontifícia Universidade Católica de São Paulo e a Universidade Federal de Santa Catarina com 3 artigos cada, a Universidade Federal do Rio Grande do Sul com 2 artigos e diversas outras com um número menor de artigos utilizado na amostra.

\section{Levantamento Quantitativo}

Considerando o banco de artigos científicos e periódicos da CAPES e buscando efetuar o levantamento de artigos publicados exclusivamente no campo da Administração, no período de 2009 até 2013, obtivemos uma amostra total de 32 publicações. Destas, 5 foram publicadas no ano de 2009, 4 em 2010, 5 em 2011, 11 em 2012, e, por fim, 7 em 2013. 
Aprofundando na área da administração, na tabela a seguir temos a distribuição dos artigos publicados relacionados com as principais áreas do conhecimento dentro da Administração, de acordo com a tabela de áreas do conhecimento da CAPES (Tabela 3).

Tabela 2: Distribuição dos artigos com base na área pesquisada.

\begin{tabular}{|c|c|c|}
\hline Área da Pesquisa & $N^{\circ}$ de Artigos & \% da Amostra \\
\hline Administração de Produção & 4 & $12,50 \%$ \\
\hline Mercadologia & 1 & $3,13 \%$ \\
\hline Administração Financeira & 15 & $46,88 \%$ \\
\hline Administração de Recursos Humanos & 4 & $12,50 \%$ \\
\hline Administração de Setores Específicos & 5 & $15,63 \%$ \\
\hline Outros & 3 & $9,38 \%$ \\
\hline TOTAL & 32 & $100 \%$ \\
\hline
\end{tabular}

Analisando as informações da tabela, fica evidente que a maioria das publicações estão dentro da área de Finanças/Economia, onde maior parte dos artigos tratam de estudos relacionados as contribuições das ONGs nos aspectos econômicos do país, como o PIB, e também a origem e o destino das verbas vindas dessas organizações. Logo em seguida vem outras áreas como empreendedorismo, recursos humanos e organizações, sistemas e métodos, onde já fica visível que são áreas com um menor número de pesquisas e publicações, porém, áreas como logística e marketing estão em um déficit muito maior, são áreas que praticamente não possuem artigos publicados. O campo "outros", se refere a pesquisas que possui uma visão geral, não se mantendo em uma área específica, mas em várias delas, como pode ser visto na tabela abaixo.

Tabela 3: Artigo com mais de uma área de pesquisa dentro do campo da administração.

\begin{tabular}{|l|l|c|}
\hline \multicolumn{1}{|c|}{ Título do Artigo } & \multicolumn{1}{|c|}{ Área Relacionada } & Ano \\
\hline $\begin{array}{l}\text { Evolução da histórica e de gestão da ONG Instituto Socioambiental Árvore no } \\
\text { período 2003-2009 }\end{array}$ & Marketing, Finanças, Recursos Humanos & 2011 \\
\hline $\begin{array}{l}\text { Perspectivas da administração no terceiro setor e oportunidades para o jovem } \\
\text { administrador }\end{array}$ & $\begin{array}{l}\text { Finanças, Recursos Humanos e } \\
\text { Empreendedorismo }\end{array}$ & 2013 \\
\hline $\begin{array}{l}\text { Captação de recursos no terceiro setor: fatores estratégicos para divulgação de } \\
\text { informações }\end{array}$ & Organizações e Métodos, Marketing e Finanças & 2012 \\
\hline
\end{tabular}

Aumentando ainda mais a especificidade do estudo, agora focando nas publicações relacionada à área de recursos humanos, podemos observar que de todos os artigos da amostra extraída do banco de artigos da CAPES, apenas 12,5\% desenvolvem estudos relacionados à gestão de pessoas. A carência de pesquisas nessa área pode demonstrar que há uma certa dificuldade de colocar em prática os processos de RH nas organizações do terceiro setor, onde há vários fatores que diferenciam tais processos de gestão de pessoas nessas organizações das empresas do primeiro e do segundo setor, como por exemplo, em muitos casos a ausência de remuneração, necessidade de implantar diferentes formas de motivação, entre outros fatores. Na tabela a seguir, podemos observar o detalhamento das publicações na área de recursos humanos, bem como a metodologia de pesquisa utilizada.

Tabela 4: Artigos da área de recursos humanos entre os anos de 2009 até 2013.

\begin{tabular}{|c|c|c|c|}
\hline Título do Artigo & Autor(es) & Metodologia & Ano \\
\hline $\begin{array}{c}\text { Sentidos das ações voluntárias: desafios e limites para a organização do } \\
\text { trabalho }\end{array}$ & $\begin{array}{c}\text { CALDANAL, A.; SOUZAL, L.; } \\
\text { CAMILOTOLL, C. }\end{array}$ & $\begin{array}{c}\text { Pesquisa de Campo } \\
\text { Qualitativa }\end{array}$ & 2012 \\
\hline $\begin{array}{c}\text { Gestão de recursos humanos no terceiro setor: um estudo descritivo das } \\
\text { organizações de belo horizonte }\end{array}$ & $\begin{array}{c}\text { ASSIS, L. B. de; VIEGAS, G.; } \\
\text { CKAGNAZAROFF, I. B. }\end{array}$ & $\begin{array}{c}\text { Pesquisa Qualitativa } \\
\text { Descritiva }\end{array}$ & 2012 \\
\hline Relações de poder em uma rede do terceiro setor: um estudo de caso & $\begin{array}{c}\text { PINTO, A. M.; JUNQUEIRA, } \\
\text { L.A.P }\end{array}$ & Pesquisa Quantitativa & 2009 \\
\hline Especificidades da gestão de pessoas no terceiro setor & $\begin{array}{c}\text { BOSE, M.; SCHOENMAKER, } \\
\text { L. }\end{array}$ & Pesquisa Bibliográfica & 2006 \\
\hline
\end{tabular}




\section{CONCLUSÕES}

Do exposto, é possível perceber que, apesar de ser nítido o avanço das pesquisas em torno das ONGs e dos modelos de gestão utilizados no terceiro setor, ainda há um rico espaço a ser investigado. Em linhas gerais, pode-se considerar que foram encontradas poucas publicações voltadas para a gestão das ONGs nos periódicos qualificados pela CAPES, nos últimos cinco anos.

Porém, dentre as limitações desse estudo, é preciso considerar a possibilidade de que, ao se limitar o universo de pesquisa aos periódicos qualificados pela CAPES, possa ter sido produzida certa refração no que diz respeito à compreensão da investigação que é produzida pela área da Administração sobre o assunto. No próprio recorte teórico, feito preliminarmente para melhor conhecer e situar o campo, foram inúmeros os trabalhos publicados apenas em eventos, tanto os de caráter nacional, promovidos pela Anpad Associação Nacional de Pesquisa e Pós-Graduação em Administração, quanto os de caráter mais local e regional, normalmente organizados pelas instituições de ensino.

A pertinência do tema recomenda o desenvolvimento de pesquisas posteriores, que permitam maior aprofundamento no tema, principalmente se considerado o contexto atual da sociedade brasileira, que vem passando por momentos de profundas mudanças e questionamentos, inclusive em relação ao papel do Estado e da sociedade civil.

Complementarmente, é preciso destacar ainda que a realização de um levantamento bibliográfico, como estratégia de introduzir alunos de graduação no universo da pesquisa científica, constitui uma medida rica de possibilidades e, ao mesmo tempo, repleta de significativos riscos.

\section{REFERÊNCIAS}

ABONG. Constituição. Estatuto Social. São Paulo: ABONG, 2013.

ASSIS, L. B.; VIEGAS, G.; CKAGNAZAROFF, I. B.. Gestão de Recursos Humanos no terceiro setor: um estudo descritivo das organizações de Belo Horizonte. Revista Eletrônica de Gestão Organizacional, Belo Horizonte, v.10, n.2, p.297-323, 2012.

BOSE, M.. Gestão de pessoas no terceiro setor. Dissertação (Mestrado em Economia e Administração) - Universidade de São Paulo, São Paulo, 2004.

BOSE, M.; SCHOENMAKER, L.. Especificidade de gestão de pessoas no terceiro setor. Revista Eletrônica de Ciência Administrativa, Campo Largo, v. 5, n.2, p.1-16, 2006.

BOURDIEU, P.. Usos sociais da ciência. São Paulo: EdUNESP, 2004.

BRASIL. Lei n. 9.970 de 23 de março de 1999. Dispõe sobre a qualificação de pessoas jurídicas de direito privado, sem fins lucrativos, como Organizações da Sociedade Civil de Interesse Público, institui e disciplina o Termo de Parceria, e dá outras providências. Brasília: DOU, 1999.

BRASIL. Lei n. 13.019 de 31 de julho de 2014. Estabelece o regime jurídico das parcerias entre a administração pública e as organizações da sociedade civil, em regime de mútua cooperação, para a consecução de finalidades de interesse público e recíproco, mediante a execução de atividades ou de projetos previamente estabelecidos em planos de trabalho inseridos em termos de colaboração, em termos de fomento ou em acordos de cooperação; define diretrizes para a política de fomento, de colaboração e de cooperação com organizações da sociedade civil; e altera as Leis nos 8.429, de 2 de junho de 1992, e 9.790, de 23 de março de 1999. Brasília: DOU, 2014.

CABRAL, A.. Movimentos Sociais, as ONGs e a militância que pensa, logo existe. São Paulo. UMESP, 1998.

CALDANA, A. C. F.; SOUZA, L. B.; CAMILOTO, C. M.. Sentidos das ações voluntárias: desafios e limites para a organização do trabalho. Psicologia \& Sociedade, Florianópolis, v.24, n.1, p.170-177, 2012. DOI: http://dx.doi.org/10.1590/S0102$\underline{71822012000100019}$

CAPES. Documento De Área 2013: Administração, Ciências Contábeis e Turismo. Brasília: CAPES, 2013.

CARDOSO, P. A.; AMORIN, M. C.. Liderança e âncoras de carreira: uma experiência de identificação dos perfis dos líderes. Pensamento \& Realidade, São Paulo, v.25, n.1, p.6178, 2010. 
CARDOSO, U. C.; CARNEIRO, V. L. N.; RODRIGUES, É. R. Q.. OSCIP: organização da sociedade civil de interesse público. Brasília: SEBRAE, 2014.

CARVALHO, C. A. P.. Preservar a identidade e buscar padrões de eficiência: questões complementares ou contraditórias na atualidade das organizações não governamentais?. REAd: Revista Eletrônica de Administração, Porto Alegre, v.6, n.2, p.1-21, 2000.

CONBOY, K.. Agility from First Principles: reconstructing the concept of agility in information system development. Information Systems Research, v.20, p.329-354, 2009.

CUNHA, J. H. C.; MATIAS-PEREIRA, J.. Captação de recursos no terceiro setor: fatores estratégicos para divulgação de informações. Revista Contemporânea de Contabilidade, Florianópolis, v.9, n.18, p.83-102, 2012. DOI: http://dx.doi.org/10.5007/2175-8069.2012v9n18p83

DURÃO, J. E.. O novo marco legal das OSC: avanço a se comemorar ou vitória de Pirro?. Rio de Janeiro: Fase Nacional, 2014.

DRUCKER, P.. As Fronteiras da Administração: onde as decisões do amanhã estão sendo determinadas hoje. São Paulo: Pioneira, 1989.

FALCONER, A. P.. A promessa do terceiro setor. São Paulo: Centro de Estudos do Terceiro Setor/Universidade de São Paulo, 1999.

FERNANDES, R. C.. O que é o terceiro setor?. Revista do Legislativo, Belo Horizonte, n.18, p.26-30, 1997.

FISCHER, A. L.; DUTRA, J. S.; AMORIM, W. A. C.. Gestão de pessoas: práticas modernas e transformação nas organizações. São Paulo: Atlas, 2010.

FONSECA, J. C. F.; ARANHA, A. V. S.. ONGs, Educação Profissional e o mito da inclusão: um debate (ainda) necessário. In: SILVA, M. A.; QUIRINO, R.. TrabalhoEducação: Diálogos entre a Educação Profissional e a Educação de Jovens e Adultos. Curitiba: CRV, 2012. p.35-60.

GARAY, S. M. C.. A Gestão de pessoas em organizações sem fins lucrativos: Principais Dilemas e Desafios. Rio de Janeiro, 2011.

GIL, A. C.. Métodos e técnicas de pesquisa social. São Paulo: Atlas, 2002.

GOHN, M. G.. Os sem-terra, ONGs e cidadania. 2 ed. São Paulo: Cortez, 2000.

GOHN, M. G.. Teorias dos movimentos sociais: paradigmas clássicos e contemporâneos. São Paulo: Loyola, 1997.

IBGE. Instituto Brasileiro de Geografia E Estatística. As Fundações Privadas e Associações sem Fins Lucrativos no Brasil 2010. Rio de Janeiro, 2012.

LANDIM, L.. Múltiplas identidades das ONGs. In: HADDAD, S.. ONGs e Universidades: desafios para a cooperação na América Latina. São Paulo: ABONG, 2002. p.17-50.

LANDIM, L.. Ações em sociedade militância, caridade, assistência, etc. Rio de Janeiro: NAU, 1998
LANDIM, L.; DURÃO, J. E. S.. A criação de um novo marco legal para o terceiro setor no Brasil. Buenos Aires: Universidade de San Andrés, 2002.

LANDIM, L.. A invasão das ONGs: do serviço invisível à profissão sem nome. Rio de Janeiro: NAU. 1993

LANDIM, L.; COTRIM, L. L.. ONGs: um perfil: cadastro das filiadas à Associação Brasileira de ONGs (ABONG). São Paulo: ABONG/ ISER, 1996.

LEWIS, D.. The management of non-governmental development organizations: an introduction. London: Routledge: 2001.

MACHADO, A. C. M.; FRANCISCONI, K.; CHAERKI, S. F.. Mapeando a abordagem estratégica em publicações acadêmicas sobre o terceiro setor. Revista Ibero Americana de Estratégia, São Paulo, v.6, n.2, p.127-136, 2007.

MAGALHÃES, N.. ONGs e IDH no Brasil: uma visão do século XXI. Dissertação (Maestría en Desarrollo Local: Estrategias Territoriales y Ambientales) - Universidad Internacional de Andalucía, Brasília, Sede Iberoamericana de Santa María de La Rábida, 2010.

MELO, A.; VALADÃO JUNIOR, V.. Conflitos e Dilemas dos Gestores de Organizações do Terceiro Setor: um estudo de multicascos. In: Encontro de Administração Pública e Governança. Anais. Salvador: ANPAD, 2008.

NOVAES, W.. Eco-92: avanços e interrogações. Estudos avançados, São Paulo, v.6, n.15, p.79-93, 1992. DOI: http://dx.doi.org/10.1590/S0103-40141992000200005

PAIVA, F.. O papel político das ONGs. In: FIEGE, H. J.. ONGs no Brasil: perfil de um mundo em mudança. Fortaleza: Fundação Konrad Adenauer, 2003. p.67-105.

PINTO, Á. M. G.; JUNQUEIRA, L. A. P.. Relações de poder em uma rede do terceiro setor: um estudo de caso. Revista de Administração Pública, Rio de Janeiro, v.43, n.8, p.34-51, 2009.

ROCHA, A. A. B. M.; TEIXEIRA, L. R.. Perspectivas da administração no terceiro setor e oportunidades para o jovem administrador. Revista Brasileira de Administração Científica, v.4, n.3, p.126-140, 2013. DOI: http://doi.org/10.6008/ESS2179-684X.2013.003.0009

RUAS, R.; ANTONELLO, C. S.; BOFF, L. H.. Os novos horizontes de gestão: aprendizagem organizacional e competências. São Paulo: Bookman, 2008.

SAMPAIO, J. R. Voluntários: um estudo sobre a motivação de pessoas e a cultura em uma organização do terceiro setor. Tese (Doutorado em Administração) - Universidade de São Paulo, São Paulo, 2004.

SILVA, C. E.; MENEZES, E. R.; BARBOSA, M. A. S.; FELIZOLA, M. P. M.. Evolução da histórica e de gestão da ONG Instituto Socioambiental Árvore no período 2003-2009. Revista Brasileira de Administração Científica, v.2, n.1, p.53-67, 2011. DOI: http://doi.org/10.6008/ESS2179684X.2011.001.0003 
TENÓRIO, F.. Gestão de ONGs: principais funções gerenciais. Rio de Janeiro: FGV, 2005.

TEODÓSIO, A. S. S.. O Terceiro Setor e a provisão de políticas sociais: desafios, perspectivas e armadilhas da relação entre organizações da sociedade civil e Estado em Minas Gerais. In: Seminário sobre Economia Mineira, 10. Anais.

Diamantina: Centro de Desenvolvimento e Planejamento Regional/UFMG, 2002.

VOESE, S. B.; REPCZUK, R. M.. Características e peculiaridades das entidades do terceiro setor. Contexto, Porto Alegre, v.11, n.19, p.31-42, 2011.

WANDERLEY, M. B.. Metamorfoses do desenvolvimento de comunidade. 2 ed. São Paulo: Cortez, 1998.
WILLETS, P.. What is a Non-Governmental Organization?. London: Centre for International Politics/School of Social Science/City University, 2006.

WEBSTER, J.; WATSON, R. T.. Analyzing The Past To Prepare For The Future: writing a literature review. MIS Quarterly, v.26, n.2, p.1-5, 2002.

ZANNI, P. P.. Estudo exploratório sobre a formação da estratégia em organizações do Terceiro Setor. Dissertação (Mestrado em Administração de Empresas) - Fundação Getúlio Vargas, São Paulo, 2005.

ZARIFIAN, P.. Organização e sistema de gestão: à procura de uma nova coerência. Gestão e Produção, São

Carlos, v.4, n.1, p.76-87, 1997. DOI:

http://dx.doi.org/10.1590/S0104-530X1997000100004 